\title{
Long-term spatial and temporal trends in frost indices in Kansas, USA
}

\author{
Aavudai Anandhi • Sriram Perumal • Prasanna H. Gowda • \\ Mary Knapp • Stacy Hutchinson • John Harrington Jr. • \\ Leigh Murray • Mary B. Kirkham • Charles W. Rice
}

Received: 23 May 2012 / Accepted: 18 May 2013 / Published online: 23 June 2013

(C) The Author(s) 2013. This article is published with open access at Springerlink.com

\begin{abstract}
Frost indices such as number of frost days (nFDs), number of frost-free days (nFFDs), last spring freeze (LSF), first fall freeze (FFF), and growing-season length (GSL) were calculated using daily minimum air temperature $\left(\mathrm{T}_{\min }\right)$ from 23 centennial weather stations across Kansas during four time periods (through 1919, 1920-1949, 1950-1979, and 1980-2009). A frost day is defined as a day with $\mathrm{T}_{\min }<0{ }^{\circ} \mathrm{C}$. The long- and short-term trends in frost indices were analyzed at monthly, seasonal, and annual timescales. Probability of occurrence of the indices was analyzed at $5 \%, 25 \%, 50 \%, 75 \%$, and $95 \%$. Results indicated a general increase in $\mathrm{T}_{\min }$ from 1900 through 2009 causing a decrease in nFDs. LSF and FFF occurred earlier and later than normal in the year, respectively, thereby resulting in an increase in GSL. In general, northwest Kansas recorded the greatest nFD and lowest $\mathrm{T}_{\min }$, whereas southeast Kansas had the lowest $\mathrm{nFD}$ and highest $\mathrm{T}_{\min }$; however, the magnitude of the trends in these indices varied with location, time period, and time scales. Based on the long-term records in most stations, LSF occurred earlier by $0.1-$ 1.9 days/decade, FFF occurred later by $0.2-0.9$ day/decade, and GSL was longer by $0.1-$
\end{abstract}

Electronic supplementary material The online version of this article (doi:10.1007/s10584-013-0794-4) contains supplementary material, which is available to authorized users.

\author{
A. Anandhi $(\bowtie) \cdot$ S. Perumal $\cdot$ M. Knapp $\cdot$ M. B. Kirkham $\cdot$ C. W. Rice \\ Department of Agronomy, Kansas State University, Manhattan, KS 66506, USA \\ e-mail: anandhi@ksu.edu \\ P. H. Gowda \\ USDA-ARS Conservation and Production Research Laboratory, Bushland, TX 79012, USA
}

\section{S. Hutchinson}

Department of Biological and Agricultural Engineering, Kansas State University, Manhattan, KS 66506, USA

J. Harrington Jr.

Department of Geography, Kansas State University, Manhattan, KS 66506, USA

L. Murray

Department of Statistics, Kansas State University, Manhattan, KS 66506, USA 
2.5 day/decade. At the $50 \%$ probability level, Independence in the south-eastern part of Kansas had the earliest LSF (6 April), latest FFF (29 October) and longest GSL (207 days). Oberlin (north-western Kansas) recorded the shortest GSL (156 days) and earliest FFF (7 October) had the latest LSF (2 May) at the $50 \%$ probability level. A positive correlation was observed for combinations of indices (LSF and GSL) and elevation, whereas a negative correlation was found between FFF and elevation.

\section{Introduction}

The number of frost or freeze days affects natural and managed ecosystems (Robeson 2002) and human activities (Liu et al. 2008) and can be indicative of changes in extreme weather and climate events over time (Meehl et al. 2004). Some of these changes affect (1) human and animal disease distribution, (2) timing and reproduction of insects and pests, (3) species diversification in wetlands (Neustupa et al. 2011), (4) crop yields (Pecetti et al. 2011), (5) seed production (Pons and Pausas 2012), (6) biomass production (Potithep and Yasuoka 2011), (7) plant photosynthesis (Oquist et al. 1993), (8) bird migration, and (9) soil decomposition and mineralization rates. Numerous indices have been used to describe frost's impact on agriculture. The timing of the first frost day in spring and fall of each year, number of consecutive frost days, and duration of frost-free days (FFDs; growing season length) are common indicators of climatic limits on agricultural production. Variations in growing season length and the timing of freeze events also can be important indicators of climatic change that may not be represented in mean conditions (Robeson 2002).

Detailed geographical and temporal variations of the frost indices can be beneficial for updating management decisions and planting date recommendations for local and regional agricultural production. Kansas has the second-most cropland acreage in the United States (Burnette et al. 2010). Changes in frost indices can be indicators of climate variations within this region. A review of frost indices is given in Table 1 in supplementary material. A number of studies have examined variations in these indices for larger regions encompassing Kansas. No studies have compared the long-term trends in frost indices for different time periods in Kansas. Therefore, the main objective of this study was to examine long-term variation and trends in frost indices such as number of frost days (nFD), number of frost-free days (nFFD), last spring freeze (LSF), first fall freeze (FFF), and growing-season length (GSL) at four different time periods for Kansas using 23 centennial weather stations.

\section{Definitions of indices}

Frost or freeze A number of definitions of a frost or freeze day are available in the days literature. In many studies, a frost day is defined as a day with a minimum air temperature $\left(\mathrm{T}_{\min }\right)$ less than a base temperature $\left(\mathrm{T}_{\mathrm{b}}\right)$. A number of values for $T_{b}$ have been chosen, some of which are presented in Table 1 in supplementary material. The most common value of $T_{b}$ is $0{ }^{\circ} \mathrm{C}$, but the "killing temperatures" for vegetation vary with plant species, and plant damage depends on the frost duration and severity (Christidis et al. 2007); therefore, a host of $\mathrm{T}_{\mathrm{b}}$, namely $-4.4{ }^{\circ} \mathrm{C},-2.2{ }^{\circ} \mathrm{C}, 5.6{ }^{\circ} \mathrm{C}$ (Robeson 2002), $2.2^{\circ} \mathrm{C}$ (Schwartz and Reiter 2000; Goodin et al. 1995, 2003), and $2{ }^{\circ} \mathrm{C}$ (Potithep and Yasuoka 2011), have been chosen to define a frost day. The European Environmental Agency (EEA) defines a frost 
day as a day with an average temperature less than $0{ }^{\circ} \mathrm{C}\left(\mathrm{T}_{\mathrm{b}}=0{ }^{\circ} \mathrm{C}\right)(\mathrm{EEA}$; http://www.eea.europa.eu/data-and-maps/indicators/global-and-europeantemperature/global-and-european-temperature-assessment-4). In this stud$\mathrm{y}$, consistent with most other studies, a frost day was defined as a day with $\mathrm{T}_{\min }<0{ }^{\circ} \mathrm{C}\left(\mathrm{T}_{\mathrm{b}}=0{ }^{\circ} \mathrm{C}\right)$.

nFDs The number of days with frost. We determined the nFDs at monthly, seasonal, and annual time scales.

nFFD The number of days without frost. We added up the nFFDs at monthly, seasonal, and annual time scales.

LSF The last day in March through May with $\mathrm{T}_{\min }<0{ }^{\circ} \mathrm{C}$ for the last time until fall. FFF The day in September through November with $\mathrm{T}_{\min }<0{ }^{\circ} \mathrm{C}$ for the first time since spring.

GSL This is defined a number of ways in the literature, but in general, the GSL is based on the onset of spring and fall. If the focus is on vegetation growth rather than resilience, higher temperature thresholds of $10{ }^{\circ} \mathrm{C}$ and $6.1{ }^{\circ} \mathrm{C}$ were considered for the onset of spring and the end of autumn (Christidis et al. 2007) based on Davis (1972). The number of days between the LSF and the FFF of the same year was used to determine GSL.

\section{Data and statistical techniques used in the study}

Daily minimum air temperature $\left(\mathrm{T}_{\min }\right)$ data from 23 centennial weather stations spread across Kansas were downloaded from the High Plains Regional Climate Center (HPRCC)'s website.

The location and period of records are provided in Fig. 1a and Table 2 in supplementary material (S.4), respectively. The records extended to the late 1800 s for a few stations, but many started observations in the early 1900s; consequently, the start dates of the records were different, but the end dates were the same (2009). The records were selected to cover non-overlapping 30-year timespans backward from 2009. The four time periods were through 1919, 1920-1949, 1950-1979, and 1980-2009. Weather stations were selected for their long-term quality based on criteria such as consistent observation times, low potential for heat-island bias, and other quality assessments (Robeson 2002; Easterling et al. 1999). More details on the data quality are provided in supplementary material (S.1).

Fitting least squares linear trends to the temperature data is the most common method used for trend analysis (Santer et al. 2000). In this study, linear trends in $T_{\min }$ and the frost indices (nFD, nFFD, LSF, FFF, and GSL) were estimated by trends to the data using linear regression. A variant of the t-test calculated the significance of the trend and accounted for the serial auto-correlation in the time series. The methods are described briefly in the Supplementary Material, and detailed information can be obtained from Wigley et al. (2006) and Santer et al. (2000).

The probability of occurrence of LSF, FFF, and GSL were calculated using exceedence $[r(x)]$ and non-exceedence probabilities $[1-r(x)]$, which in turn were calculated from their cumulative probability distribution function (CDF), $F(x)$, using Eq. 1.

$$
F(x)=\left\{\begin{array}{cl}
0 & -\infty<x<x_{i} \\
\frac{i}{n} & x_{i} \leq x<x_{n} \\
1 & x_{n} \leq x<\infty
\end{array}\right.
$$


(a)

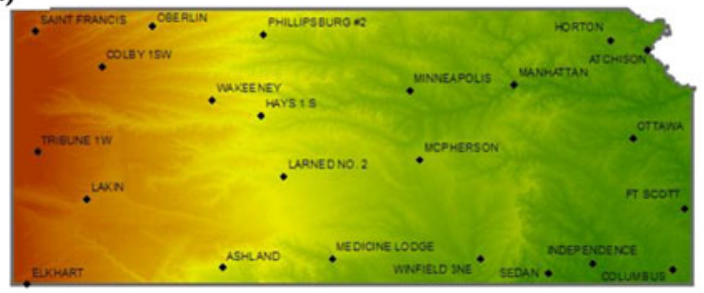

(b)

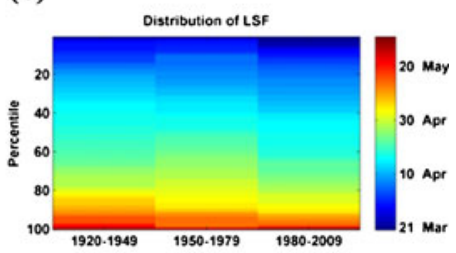

\section{- Freeze stations \\ Elevation

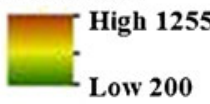

(c)

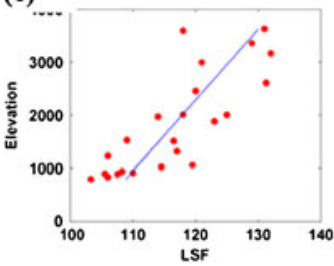

(f)

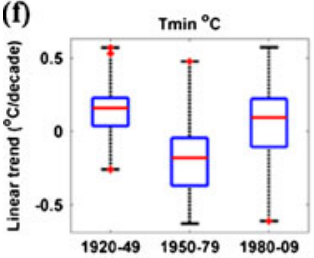

(i)

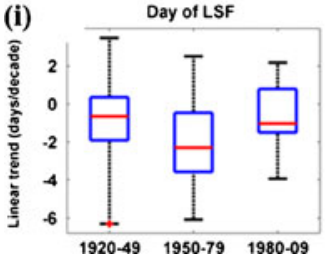

(d)

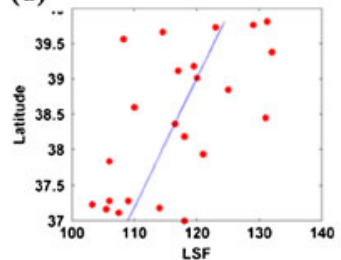

(g)
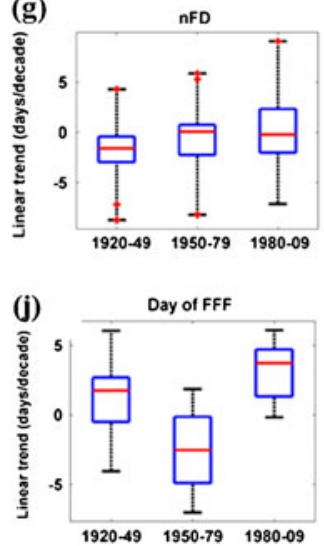

(e)
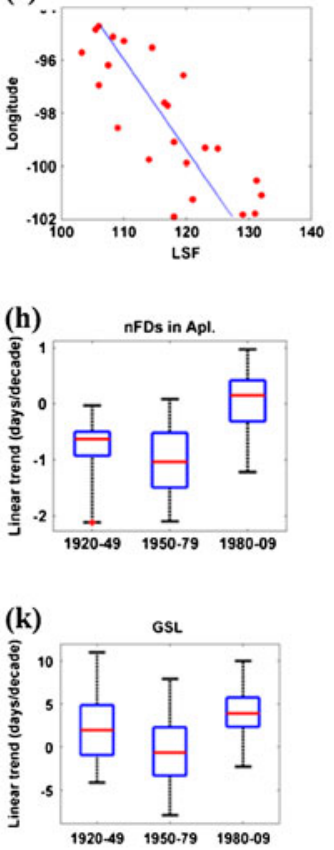

Fig. 1 a Map of the meteorological stations in Kansas used in the study. Elevation is provided in the background. b Distribution of last spring freeze (LSF) in Kansas in three time periods (1920-1949, 1950-1979, 1980-2009) across 23 stations. In these time periods, each station has 30 values of LSF. Each column in the figure represents the distribution for a time period and is made using 690 values $(30 \times 23)$. $\mathbf{c}-\mathbf{e}$ Plot of day of LSF (x-axis) vs. elevation, latitude, and longitude (y-axis) for 23 stations. $\mathbf{f}-\mathbf{k}$ Distribution of trends/decade across three time periods (1920-1949, 1950-1979, 1980-2009) across 23 stations for Tmin and frost indices [number of frost days (nFD), last spring freeze (LSF), first fall freeze (FFF), growing season length (GSL)] using boxplots. Each boxplot for a time period comprises of 23 linear trend values from stations

where $\mathrm{x}$ is the values of the predictand at different time periods. Sample size for the short term was 30 years $(n=30)$; for the long term, size varied $(n=100-120)$ depending on the period of records. 


\section{Results}

\subsection{Minimum air temperature $\left(\mathrm{T}_{\min }{ }^{\circ} \mathrm{C}\right)$}

Monthly mean and distribution of daily $\mathrm{T}_{\min }$ among the 23 stations spread across the entire state of Kansas for the four time periods is plotted in Fig. 2. January had the most days with low $\mathrm{T}_{\min }$ values as well as the lowest daily $\mathrm{T}_{\min }$ values, whereas June recorded the highest $\mathrm{T}_{\min }$ value. Northwest Kansas (Oberlin) had the lowest $\mathrm{T}_{\min }$ values, and southeast Kansas (Columbus) had the highest $\mathrm{T}_{\text {min }}$ values for the most time periods and months. The western Kansas stations are expected to record lower $\mathrm{T}_{\min }$ than those in eastern Kansas because they are located at relatively higher elevation (Fig. 1a; Table 2 supplementary material). Variation in $\mathrm{T}_{\min }$ among the stations for all four time periods was nearly constant $\left(5\right.$ to $\left.6{ }^{\circ} \mathrm{C}\right)$ across the

(a)
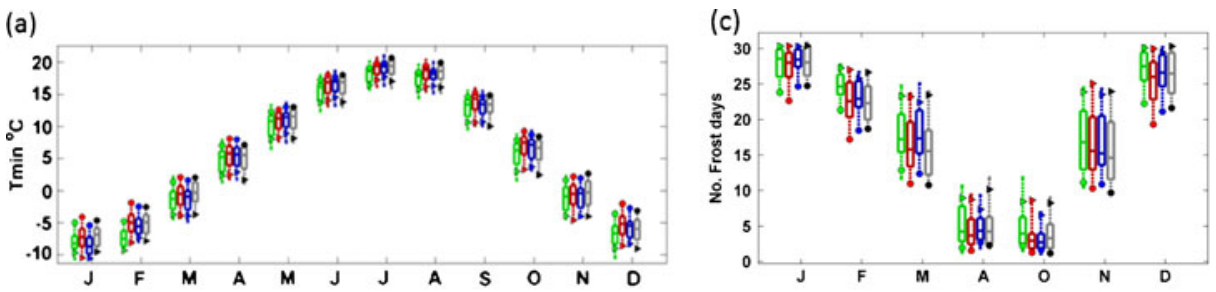

(b)

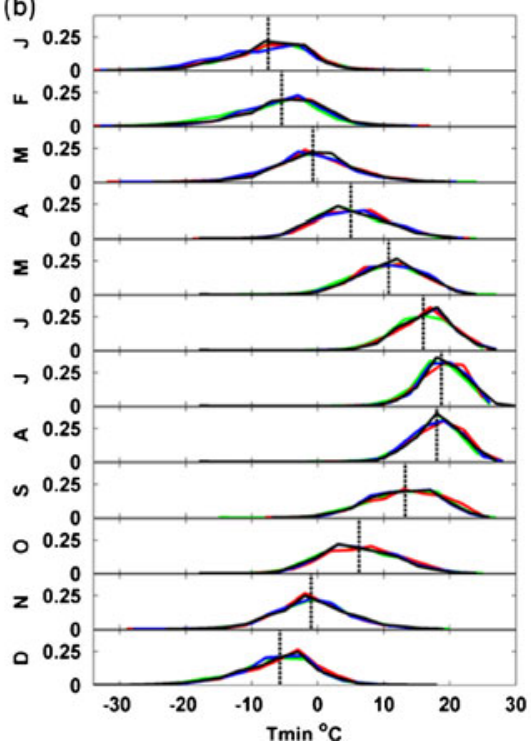

(d)

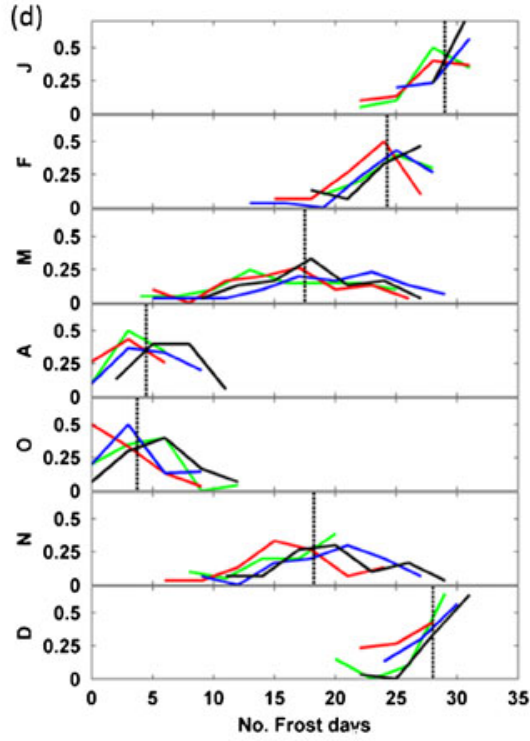

Fig. 2 Variation of (a-b) minimum temperature (Tmin) and (c-d) number of frost days (nFDs) across the 23 centennial stations in Kansas four time periods (through 1919, 1920-1949, 1950-1979, 1980-2009). a, c Boxplots of the mean monthly Tmin and nFDs; $\mathbf{b}$, $\mathbf{d}$ monthly probability density functions (PDFs) of daily Tmin and nFDs. Mean values for entire time period of record are plotted as dotted vertical lines. Each boxplot comprises 23 monthly mean values. Each PDF for a month represents the distribution of the monthly values across the 23 stations for a time period. For example, the PDF in January for the 30-year time period (19802009 ) is the distribution of 690 values ( $30 \mathrm{nFDs}$ in January $\times 23$ stations). In the boxplot, Tmin and nFDs for the Oberlin station are represented by a triangle, and Tmin and nFDs for the Columbus station are represented by a circle. The four colors represent four time periods (green: through 1919; red: 1920-1949; blue: 19501989; gray: 1980-2009) 
months (Fig. 2a-b). We observed no clear difference among the four time periods in the monthly distributions of $\mathrm{T}_{\min }$ values.

Differences in long- and short-term linear trends in monthly, seasonal, and annual $\mathrm{T}_{\min }$ were observed at all 23 stations. Trends in annual average $\mathrm{T}_{\min }$ for all 23 stations (are shown in Fig. 3 in supplementary material. Among the stations, 12 exhibited (11 were significant) an increase of $0.1{ }^{\circ} \mathrm{C} /$ decade (Elkhart had $0.2{ }^{\circ} \mathrm{C} /$ decade increase), nine stations had no change, and the remaining two stations showed a significant decrease of $0.1{ }^{\circ} \mathrm{C} /$ decade in long-term $\mathrm{T}_{\min }$ values (Ashland and Colby). In the winter season (DJF), a few stations (7) showed an increasing $\mathrm{T}_{\min }$ long-term trend (Saint Francis, Atchison, Minneapolis, Lakin, Larned, and Elkhart). More than half of the stations (13) exhibited no change, whereas the remaining three stations (Ashland, Colby, and Sedan) had a 0.1 to $0.2{ }^{\circ} \mathrm{C} /$ decade decrease in $\mathrm{T}_{\text {min }}$ (data not shown). A guide for interpreting the results presented in Figs. 3-6 is provided in Fig. 1 in the supplementary material.

\section{$4.2 \mathrm{nFD}$ and $\mathrm{nFFDs}$}

The nFDs among the 23 stations for the four time periods are shown in Fig. 2c-d. In general, frost occurs in Kansas during 7 months: January through April and October through December; however, a few instances of frost occurrences were found in May, August, and September. In general, January had the highest nFDs, followed by December and April, and October had the fewest $n F D$ s. Consistent with results for $\mathrm{T}_{\min }$, northwest Kansas (Oberlin) had the greatest $\mathrm{nFD}$, and southeast Kansas (Columbus) had the least nFD for most time periods and months. Interestingly, Fig. 2c-d shows that, except for the month of March, all other months with frost had a higher frequency of nFDs in the most recent time period (1980-2009). The shift in the distribution toward higher nFDs was more pronounced in

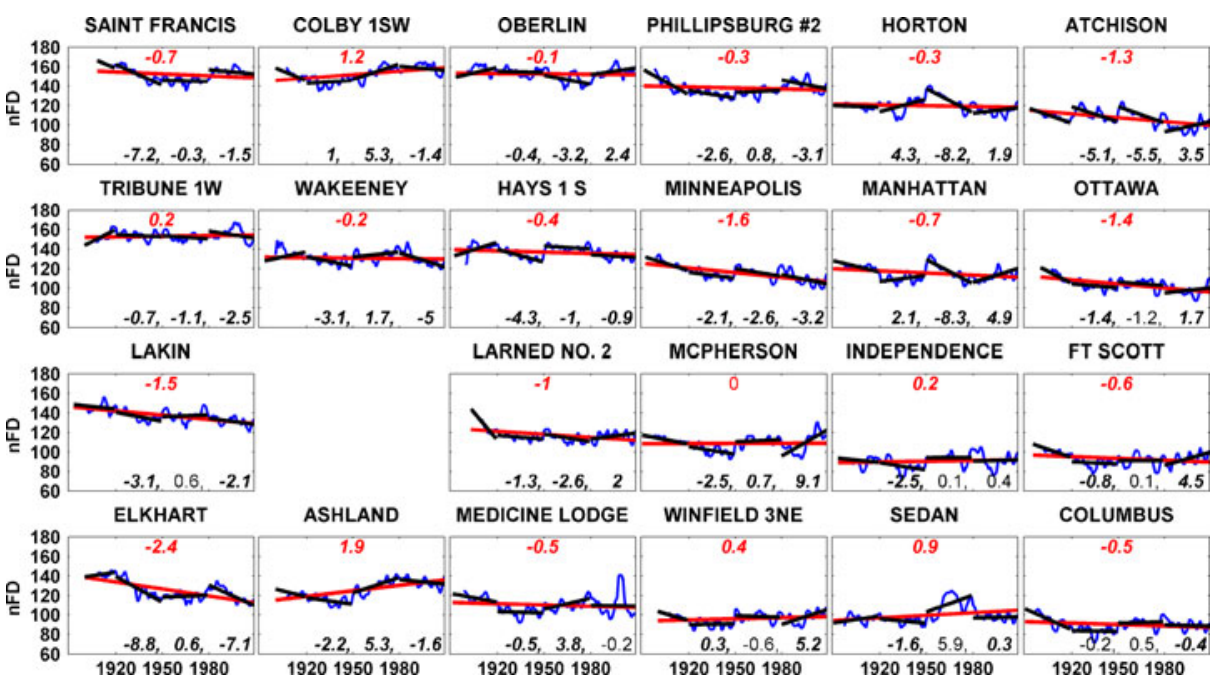

Fig. 3 Five-year moving averages (thin blue lines) and linear trends in the number of frost days (nFDs) in the 23 centennial stations in Kansas are shown. A single trend was calculated for the entire period of record (red line), and multiple trend lines were calculated for three time periods (1920-1949, 1950-1979, 1980-2009) (short black lines). The subplots in the figure are arranged in their approximate geographical locations. The numbers in the subplots represent the trend in days/decade, and significant trends are in italics and bold. The long-term trend value is in red (top), and the three values in black (bottom) are the short-term trends for the three time periods 
April (late spring) and October (mid-fall) than in other months with frost occurrence, which indicates that during April, the most recent period (1980-2009) has a higher frequency of nFDs ( 5 to $11 /$ month) compared with previous time periods. A shift in the lower extreme distribution (fewer nFFDs) can be observed from the PDFs in Fig. 2 in supplementary material.

We observed differences in long-term and short-term linear trends in monthly, seasonal, and annual nFDs in all stations across the state. Figure 3 provides the annual trends for all 23 stations. From the long-term annual trends, we can observe an overall decrease (16 of 23 stations) in nFDs. The overall decreases in nFDs vary from 0.1 day/decade (Oberlin) to 2.4 day/decade in Elkhart, which also had the largest increase in $\mathrm{T}_{\min }\left(0.2{ }^{\circ} \mathrm{C}\right.$ change per decade) in the state. Six stations showed an increase in nFDs. Among them, Ashland had the highest increase (1.9 day/decade), Tribune and Independence had the least increase (0.2 day/decade), and no change was observed at McPherson. Interestingly, most stations in eastern Kansas showed an increase in nFDs in the most recent time period, whereas stations in western Kansas showed a decrease; however, a similar pattern did not occur in the long-term trends. Trends of nFDs varied among the seasons (Fig. 4 in supplementary material). More stations in the state recorded a decrease in nFDs in the fall (16 stations), followed by spring (15 stations) and winter (11 stations; 9 significant). We observed variations in short- and long-term, monthly, and seasonal trends. These differences are illustrated in spring in Fig. 5 in supplementary material.

\subsection{Last spring freeze (LSF) and first fall freeze (FFF)}

In this section, the results of the trends and their significance and the probability of occurrences for long (entire record period) and short (three 30-year periods) periods of records are presented for LSF and FFF.

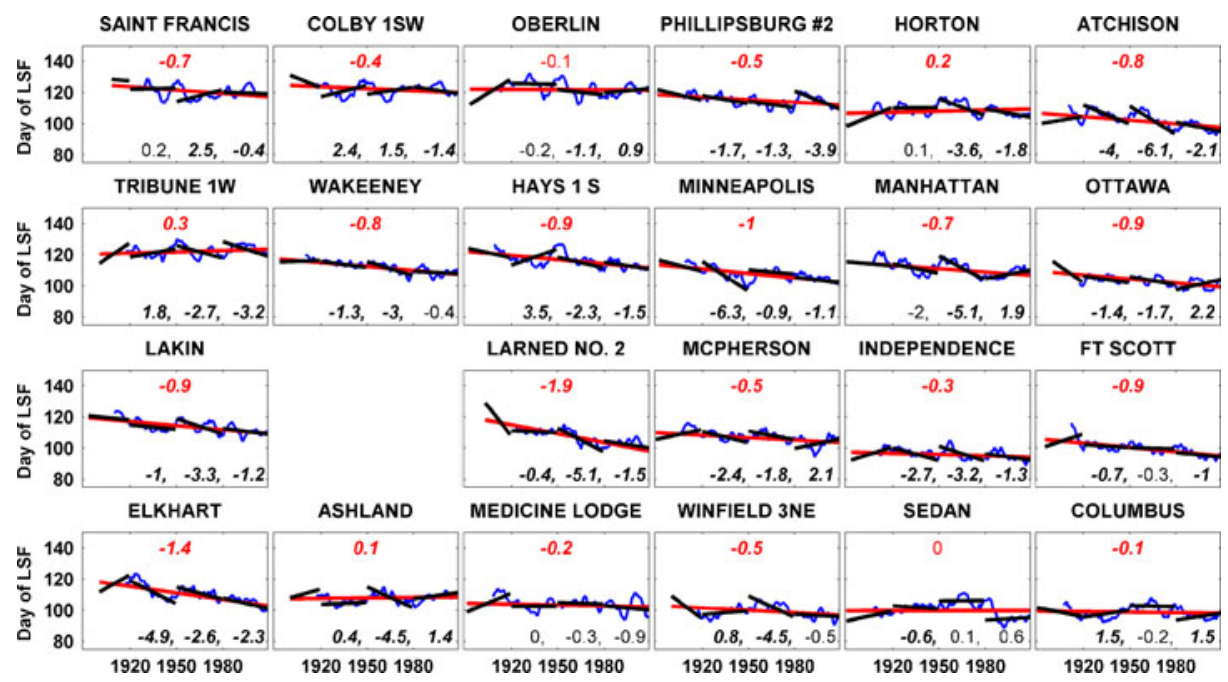

Fig. 4 Ten-year moving averages (thin blue lines) and linear trends in the day of last spring freeze (LSF) at the 23 centennial stations in Kansas are shown. A single trend was calculated for the entire period of record (red line), and multiple trend lines were calculated for three time periods (1920-1949, 1950-1979, 1980-2009) (short black lines). The subplots in the figure are arranged in their approximate geographical locations. The numbers in the subplots represent the trend in days/decade, and significant trends are in italics and bold. The long-term trend value is in red (top), and the four values in black (bottom) are the short-term trends for the four time periods 


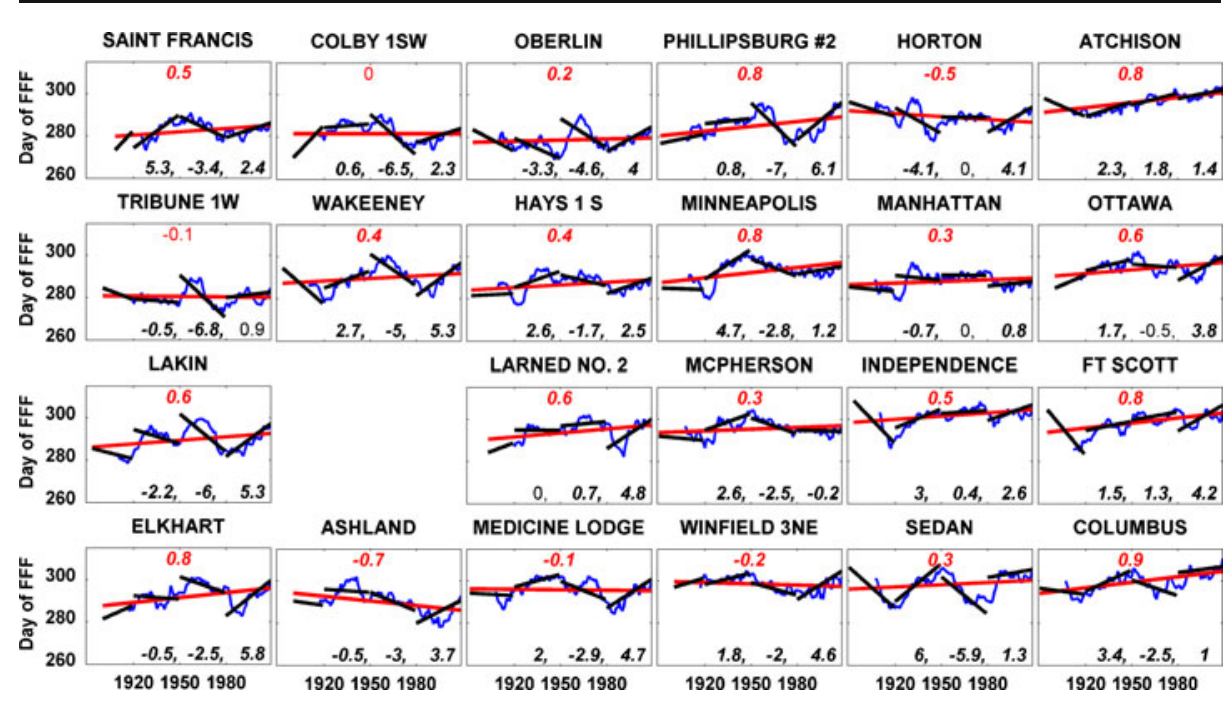

Fig. 5 Ten-year moving averages (thin blue lines) and linear trends in the day of first fall freeze (FFF) at the 23 centennial stations in Kansas are shown. A single trend was calculated for the entire period of record (red line), and multiple trend lines were calculated for three time periods (1920-1949, 1950-1979, 1980-2009) (short black lines). The subplots in the figure are arranged in their approximate geographical locations. The numbers in the subplots represent the trend in days/decade, and significant trend are in italics and bold. The long-term trend value is in red (top), and the three values in black (bottom) are the short-term trends for the three time periods

Time series and trend lines for LSF at each of the 23 stations are plotted in Fig. 4. The LSF occurred in April in most years. Most stations (19, out of which 18 had significant change) in the state show a decrease of 0.1 to 1.9 days/decade, but Sedan recorded no change. The stations at Horton, Ashland, and Tribune had a slight increase of 0.1 to 0.3 days/decade in LSF. The largest decrease in LSF was recorded at the Larned station in central Kansas. The eastern part of the state recorded its LSF earlier than the western part. There were positive correlations between (1) station elevation and day of LSF at 50 (Fig. 1c), (2) station latitude and day of LSF (Fig. 1d), and (3) station longitude and day of LSF (Fig. 1e). Also, a change was observed in elevations along east-west (longitudes) and northsouth (latitudes) directions. Elevations of the southeastern stations are lower than those in the northwestern part of the state and recorded an earlier LSF as expected. Elevation differences can be seen in Fig. 1a.

For the study period, the probability of LSF for individual stations was calculated and provided in supplementary material (Table 3). It was observed that the earliest LSF occurred in Independence (eastern part) on 28 February 1905. The earliest LSF in the state was also in Independence on 20 March, 29 March, 6 April, 13 April, and 23 April at 5 \%, 25 \%, 50 \%, $75 \%$, and $95 \%$ probabilities, respectively. The latest LSF occurred in Medicine Lodge on 31 May 1998. In general, LSF occurred in Colby (western part) at a later part of the study period on 15 April, 2 May, 12 May, and 20 May at $5 \%, 50 \%, 75 \%$, and $95 \%$ probabilities, respectively, and it occurred in Tribune on 24 April at $25 \%$ probability. These results indicate a one-month lag in LSF occurrence within the state.

The probability distribution of LSF across 23 stations in the three shorter time periods is plotted in Fig. 1b. The figure shows that the LSF generally occurred earlier in the spring season.

Time series and trend lines in FFF are illustrated in Fig. 5. The FFF occurred in October in most years. In contrast to LSF, the western part of the state recorded its FFF earlier than that in the 
eastern part, resulting in a shorter growing season in the west. This result is related to the eastwest and north-south change in elevations in the state (Fig. 6a-c in supplementary material); the southeastern stations are at a lower elevation than those in the northwestern part of the state. In general, long-term FFF increased significantly at 17 stations, ranging from 0.2 to 0.9 day/decade. Columbus recorded the highest increase of 0.9 day/decade. Colby had no change in FFF, and five stations (Ashland, Medicine Lodge, Winfield, and Horton) had a reduction in FFF by 0.1 to 0.7 day/decade. The decrease in FFF was not significant in Tribune. This general increase in FFF in the state indicates that the first frost day is occurring later in the season. Although some stations show a long-term decrease in FFF, LSF increased consistently across all stations for 1980-2009, indicating a shift toward a later occurrence of the first frost days in the fall.

The probability (exceedence probability statistics) of FFF for individual stations for the entire period of record is provided in Table 4 in supplementary material. Among the stations in the state, the earliest FFF occurred in Oberlin (western part) on 16 September, 27 September, 7 October, 13 October, and 25 October at $5 \%, 25 \%, 50 \%, 75 \%$, and $95 \%$ probabilities, respectively. The latest FFF occurred in Independence (eastern part) on 9 October, 21 October, 29 October, and 5 November at $5 \%, 50 \%, 75 \%$, and $95 \%$ probabilities, respectively, which indicates a 15-20 day lag in FFF occurrence within the state. Although many stations indicate a later FFF, the distribution of FFF across 23 stations in three short time periods (Fig. 6d in supplementary material) individually does not clearly indicate that the FFF is occurring later in the fall.

\subsection{Growing season length (GSL)}

We calculated GSL for each station, and the time series and trend lines are plotted in Fig. 6. In general, the growing season extended from late April to early October. Most stations (20)

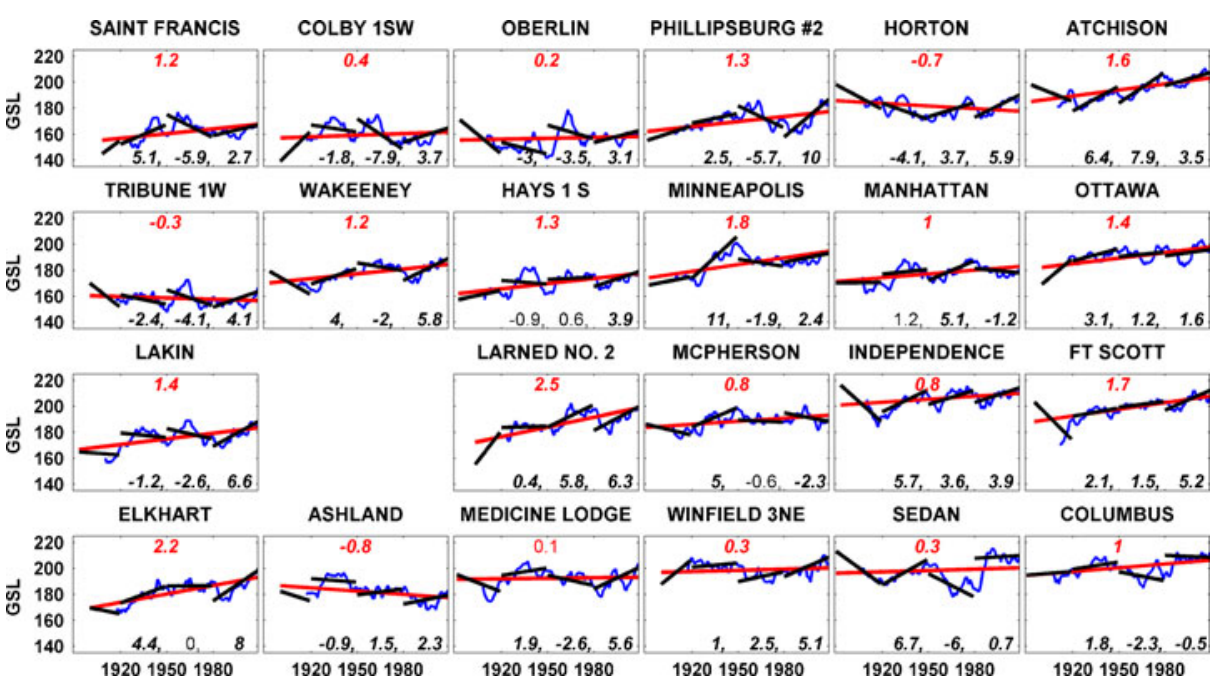

Fig. 6 Ten-year moving averages (thin blue lines) and linear trends in the growing season length (GSL) at the 23 centennial stations in Kansas are shown. A single trend was calculated for the entire period of record (red line), and multiple trend lines were calculated for three time periods (1920-1949, 1950-1979, 1980-2009) (short black lines). The subplots in the figure are arranged in their approximate geographical locations. The numbers in the subplots represent the trend in days/decade, and significant trend are in italics and bold. The long-term trend value is in red (top), and the three values in black (bottom) are the short-term trends for the three time periods 
in the state showed an increase in GSL (0.1 to 1.9 day/decade), with only Horton, Ashland, and Tribune showing a slight decrease ( 0.1 to 0.8 day/decade). The highest increase in GSL was in Larned (2.5 days/decade). In general, the eastern part of the state has a longer growing season than the western part (earlier LSF and later FFF). This can be attributed to east-west and north-south elevation gradients in the state (Fig. 7a-c in supplementary material); the southeastern stations are at a lower elevation than those in the northwestern part of the state.

The probability of GSL for individual stations is provided in Table 5 in supplementary material. In general, the stations in the western part of the state (Colby, Oberlin, and Tribune) had the shortest GSL of about 130,143, 156, 171, and 182 days at $5 \%, 25 \%, 50 \%, 75 \%$, and $95 \%$ probabilities, respectively. The longest GSL of 177, 195, 207, 216, and 233 days occurred in Independence (eastern part) at $5 \%, 25 \%, 50 \%, 75 \%$, and $95 \%$ probabilities, respectively. The distribution of GSL across the 23 stations in the three short time periods (Figs. 7d and 10 in supplementary material) indicates that, in general, the length of GSL is increasing. Based on these figures, it can be concluded that the growing season starts earlier in the spring season and extends later into the fall season in Kansas.

The distribution of trends for $\mathrm{T}_{\min }$ and frost indices (nFD, LSF, FFF, GSL) across the three time periods (1920-1949, 1950-1979, and 1980-2009) were studied using boxplots (Fig. 1f-k). There was no clear monotonically increasing or decreasing rate of change across the periods; however, the median rate of change during the 1950-1979 period was lower (e.g., $\mathrm{T}_{\mathrm{min}}, \mathrm{nFDs}$ in April, LSF, FFF, GSL) when compared with the other two time periods. At $50 \%$ probability, the rate of change in Tmin, nFDs in April, LSF, and FFF during the 1980-2009 period was higher when compared with the 1950-1979 period, while the rate of change for GSL was less. At $50 \%$ probability, the mean monthly $\mathrm{T}_{\min }$ during the winter, early spring, and late fall seasons during 1950-1979, were lower when compared with the 1920-1949 and 1980-2009 periods (Fig. 2).

\section{Discussion and conclusion}

Results from the analysis (both short-term and long-term) of $\mathrm{T}_{\min }$ and frost indices from 23 centennial stations indicated general increases in average $\mathrm{T}_{\min }, \mathrm{nFFD}$, and GSL and a reduced $\mathrm{nFD}$. An observed increase in GSL was due to earlier timing of LSF in the year, whereas the FFF occurred later in the year. While considering the entire period of records, we observed about a one-month lag in LSF occurrence within the state, with the earliest occurrence recorded in Independence (eastern part) between 20 March and 23 April at $5 \%$ and $95 \%$ probabilities, respectively, and the latest occurrence in Colby (western part) between 15 April and 20 May at $5 \%$ and $95 \%$ probabilities, respectively. About a onemonth lag in the occurrence of FFF also occurred within the state, with the earliest occurrence in Oberlin (western part) between 16 September and 25 October at $5 \%$ and $95 \%$ probabilities, respectively, and the latest occurrence of FFF in Independence (eastern part) between 9 October and 5 November at $5 \%$ and $95 \%$ probabilities, respectively. In general, the stations in the western part of the state (Saint Francis, Colby, Oberlin, and Tribune) had the shortest 130 and 182 days at $5 \%$ and $95 \%$ probabilities, respectively, whereas the longest GSL of 177 and 233 days occurred in Independence (eastern part of the state) at $5 \%$ and $95 \%$ probabilities, respectively.

The trends in frost indices were found to vary across the stations, time periods, and time scales (monthly, seasonal, and annual). Based on the long-term records, LSF occurred earlier at the rate of 0.1 to 1.9 days/decade, FFF occurred later at the rate of 0.2 to 0.9 day/decade, 
and GSL was longer at the rate of 0.1 to 1.9 day/decade in most stations. No clear monotonically increasing or decreasing trends were found in the indices across all three time periods. Decreases in nFDs are often assumed to be linked to increasing nighttime temperature; however, in a single location, regional patterns are correlated to various interrelated physical processes such as changes in regional atmospheric circulation, topography, etc. (Meehl et al. 2004; Goodin et al. 1995, 2004). Advection frosts are most common in Kansas during the winter months and occur when a cold mass of air moves into an area and lowers the surface temperature below freezing (Goodin et al. 1995, 2004). Higher elevations and drier air in the northwest yield earlier FFF and later LSF. This spatial and temporal pattern is similar to that found in Oklahoma (Johnson and Duchon 1995). Within Kansas, hillier areas, such as the Flint Hills region, tend to have a more complex spatial pattern and earlier fall and later spring freezes. These results are also consistent with results reported by Rahimi et al. (2007).

Our results added local precision to the earlier findings that encompassed larger areas, including Kansas (Feng and $\mathrm{Hu}$ 2004). The long-term trend in our study indicated a general increase of $0.1^{\circ} \mathrm{C} / \mathrm{decade}$ for a period of more than 100 years (up to 2009), which, except for a few local variations, demonstrates that the local trend was slightly less than the global increase of $0.2{ }^{\circ} \mathrm{C} /$ decade increase in global $\mathrm{T}_{\text {min }}$ for the period 1950-2004 (based on Vose et al. 2005). Rounding of trend values to a second decimal place resulted in trends in the range of $-0.05-0.05{ }^{\circ} \mathrm{C} /$ decade at some stations to have a trend of zero. Still lower trends in summer $\mathrm{T}_{\min }\left(0.05^{\circ} \mathrm{C} /\right.$ decade and $0{ }^{\circ} \mathrm{C} /$ decade $)$ can be observed in Kansas from the contour plots in Fig. 6b in Feng and Hu (2004). Reduction in nFDs during 1950-95 was observed in the land areas in the northern hemisphere in North America (Kiktev et al. 2003). Variations in the trends in nFDs across time periods (1951-2010) and stations in the region are consistent to the results from Terando et al. (2012a). They found the pattern observed in parts of the central USA for frost days are consistent with the so-called "warming hole" (the largest area of cooling in the central US).

Christidis et al. (2007) found an increase in GSL (1.5 days/decade) in North America, with negative trends in certain parts due to local variations for the period 1950-1999. Their results showed that the increase in GSL was due to an earlier start of the growing season (decrease in LSF, or earlier spring) and no change in the end of growing season, and these results are in agreement with Schwartz and Reiter (2000). They observed earlier spring by 56 days during a 35-year (1959-93) record in North America, but they found LSF was highly variable and changed in a non-linear fashion, even though they defined a frost day as a day with $\mathrm{T}_{\min }<-2.2^{\circ} \mathrm{C}$. In Fig. 7 in Feng and $\mathrm{Hu}$ (2004), the trends for Kansas during 19512000 show an earlier start of spring by 0.5 to 2.5 days/decade, 0.5 day/decade change in FFF, and -0.5 to 1.5 days/decade change in GSL. Our results are consistent with Feng and $\mathrm{Hu}$ (2004), and they indicate that the increase in GSL was due to both an earlier start of the growing season and a later ending of the growing season (increase in FFF) in most parts of the state, with some negative trends in certain parts of the state due to local variations. Our results differ, however, from Schwartz and Reiter (2000) and Christidis et al. (2007), which showed no change in FFF. These differences could be because continental-scale results are only rough guides of regional changes (Christidis et al. 2007).

Little work has been done on the synoptic climatology of freeze events at the start and/or end of the growing season for Kansas. Last frosts in the spring are likely related to clear skies and weak winds that occur with $\mathrm{cP}$ air mass presence following the passage of a wave cyclone that advects cold and dry air into the central Plains. For some Kansas weather stations that are located in river valley locations, cold air drainage along with a decoupling of the boundary layer assist in creating spatially anomalous temperatures in the valley bottoms 
during periods of weak southerly winds. It is likely that an anomalous northerly component to the upper-level flow pattern and strong cold air advection associated with the backside of a vigorous wave cyclone is needed to generate an advection frost, bringing in the dry air for the first freeze in autumn (Goodin et al. 1995, 2004).

Most of the work on teleconnections between sea surface temperature or pressure anomalies, whether one is thinking about ENSO, the NAO, or the AO, has addressed the winter and summer seasons (Ropelewski and Halpert 1986; Hurrell and van Loon 1997), resulting in a need for research to examine the transition seasons in more detail. Goodin et al. (2003) examined the weak seasonal correlations between teleconnection patterns that do exist for ENSO, NAO, and other indexes in relation to grassland productivity at the Konza Prairie Biological Station in the Flint Hills. Strongest correlations, which explained less than $25 \%$ of the variance, were associated winter and summer.

To attribute the changes in the frost indices to either natural and/or anthropogenic forcing, previous studies have forced the global climate models (GCMs) with major natural and anthropogenic forcings that act on the climate system in the twentieth century. For the period 1950-1999, Christidis et al. (2007) attributed the change in GSL in North America, to just anthropogenic forcing, while Meehl et al. (2007) attributed the decrease of nFDs and an increase in GSL in USA, to anthropogenic and natural forcings. Leibensperger et al. (2012) suggests that US anthropogenic aerosols may be the drivers of changes in circulation causing central US cooling. The difficulties and limitations in attributing observed changes to the external forcings at regional scales are discussed in a number of studies (Stott et al. 2010; Wu and Karoly 2007; Terando et al. 2012a; Terando et al. 2012b). Attributing the changes in Kansas to external forcings and comparing these changes with the model simulations (past and future) and AGMIP can be a continuation of this study and is deferred for future work.

Acknowledgments This material is based upon work supported by the National Science Foundation under Award No. EPS-0903806, matching support from the State of Kansas through Kansas Technology Enterprise Corporation and Ogallala Aquifer Program (research and education consortium) grant No.58-6209-9-052. This is contribution number 12-421-J from the Kansas Agricultural Experiment Station. In addition, we express our gratitude to the three anonymous reviewers whose suggestions greatly enhanced the earlier draft of the paper.

Open Access This article is distributed under the terms of the Creative Commons Attribution License which permits any use, distribution, and reproduction in any medium, provided the original author(s) and the source are credited.

\section{References}

Burnette DJ, Stahle DW, Mock CJ (2010) Daily-mean temperature reconstructed for Kansas from early instrumental and modern observations. J Clim 23(6):1308-1333. doi:10.1175/2009jcli2445.1

Christidis N, Stott PA, Brown S, Karoly DJ, Caesar J (2007) Human contribution to the lengthening of the growing season during 1950-99. J Clim 20(21):5441-5454. doi:10.1175/2007jcli1568.1

Davis NE (1972) The variability of the onset of spring in Britain. Q J R Meteorol Soc 98(418):763-777. doi:10.1002/qj.49709841805

Easterling DR, Karl TR, Lawrimore JH, Del Greco SA (1999) United States historical climatology network daily temperature, precipitation, and snow data for 1871-1997, ORNL/CDIAC-118, NDP-070, Carbon Dioxide Information Analysis Center, Oak Ridge National Laboratory, U.S. Department of Energy

Feng S, Hu Q (2004) Changes in agro-meteorological indicators in the contiguous United States: 1951-2000. Theor Appl Climatol 78(4):247-264. doi:10.1007/s00704-004-0061-8

Goodin DG, Mitchell JE, Knapp MC, Bivens RE (1995, 2004) Climate and weather atlas of Kansas. Kansas Geological Survey Publications Educational series 12 
Goodin D, Fay P, McHugh M (2003) Climate variability in tallgrass prairie at multiple timescales: Konza Prairie Biological Station. In: Greenland D, Goodin D, Smith R (eds) Climate variability and ecosystem response at long-term ecological research sites. Oxford University Press, New York

Hurrell J, van Loon H (1997) Decadal variations in climate associated with the North Atlantic Oscillation. Clim Chang 36:301-326

Johnson H, Duchon C (1995) Atlas of Oklahoma climate. University of Oklahoma Press, Norman

Kiktev D, Sexton DMH, Alexander L, Folland CK (2003) Comparison of modeled and observed trends in indices of daily climate extremes. J Clim 16(22):3560-3571. doi:10.1175/1520-0442(2003)016<3560: comaot $>2.0 . \operatorname{co} ; 2$

Leibensperger E, Mickley L, Jacob D, Chen W, Seinfeld J, Nenes A, Adams P, Streets D, Kumar N, Rind D (2012) Climatic effects of 1950-2050 changes in US anthropogenic aerosols- Part 2: climate response. Atmos Chem Phys 12(7):3349-3362

Liu B, Henderson M, Xu M (2008) Spatiotemporal change in China's frost days and frost-free season, 19552000. J Geophys Res 113(D12), D12104. doi:10.1029/2007jd009259

Meehl G, Tebaldi C, Nychka D (2004) Changes in frost days in simulations of twentyfirst century climate. Clim Dyn 23:495-511. doi:10.1007/s00382-004-0442-9

Meehl GA, Arblaster JM, Tebaldi C (2007) Contributions of natural and anthropogenic forcing to changes in temperature extremes over the United States. Geophys Res Lett 34(19), L19709

Neustupa J, Černá K, Št'astný J (2011) The effects of aperiodic desiccation on the diversity of benthic desmid assemblages in a lowland peat bog. Biodivers Conserv 20(8):1695-1711. doi:10.1007/s10531-011-0055-7

Oquist G, Hurry VM, Huner NPA (1993) Low-temperature effects on photosynthesis and correlation with freezing tolerance in spring and winter cultivars of wheat and rye. Plant Physiol 101:245-250

Pecetti L, Annicchiarico P, Abdelguerfi A, Kallida R, Mefti M, Porqueddu C, Simões NM, Volaire F, Lelièvre F (2011) Response of Mediterranean tall fescue cultivars to contrasting agricultural environments and implications for selection. J Agron Crop Sci 197(1):12-20. doi:10.1111/j.1439-037X.2010.00443.x

Pons J, Pausas J (2012) The coexistence of acorns with different maturation patterns explains acorn production variability in cork oak. Oecologia :1-9. doi:10.1007/s00442-011-2244-1

Potithep S, Yasuoka Y (2011) Application of the 3-PG model for gross primary productivity estimation in deciduous broadleaf forests: a study area in Japan. Forests 2(2):590-609

Rahimi M, Hajjam S, Khalili A, Kamali G, Stigter C (2007) Risk analysis of first and last frost occurrences in the Central Alborz region, Iran. Int J Climatol 27(3):349-356

Robeson SM (2002) Increasing growing-season length in Illinois during the 20th century. Clim Chang 52(1):219-238. doi:10.1023/a:1013088011223

Ropelewski CF, Halpert MS (1986) North American precipitation and temperature patterns associated with the El Nino/ Southern oscillation (ENSO). Mon Weather Rev 114:2352-2362

Santer BD, Boyle J, Hnilo J, Taylor K, Wigley T, Nychka D, Gaffen D, Parker D (2000) Statistical significance of trends and trend differences in layer-average atmospheric temperature time series. J Geophys Res 105(D6):7337-7356

Schwartz MD, Reiter BE (2000) Changes in North American spring. Int J Climatol 20(8):929-932. doi:10.1002/1097-0088(20000630)20:8<929::aid-joc557>3.0.co;2-5

Stott PA, Gillett NP, Hegerl GC, Karoly DJ, Stone DA, Zhang X, Zwiers F (2010) Detection and attribution of climate change: a regional perspective. Wiley Interdiscip Rev Clim Chang 1(2):192-211

Terando A, Easterling W, Keller K, Easterling D (2012a) Observed and modeled twentieth-century spatial and temporal patterns of selected agro-climate indices in North America. J Clim 25(2):473

Terando A, Keller K, Easterling WE (2012b) Probabilistic projections of agro-climate indices in North America. J Geophys Res: Atmospheres (1984-2012) 117(D8)

Vose RS, Easterling DR, Gleason B (2005) Maximum and minimum temperature trends for the globe: An update through 2004. Geophys Res Lett 32:L23822

Wigley TML, Santer B, Lanzante J (2006) Appendix A: statistical issues regarding trends. Temperature trends in the lower atmosphere: steps for understanding and reconciling differences, 129-139

Wu Q, Karoly DJ (2007) Implications of changes in the atmospheric circulation on the detection of regional surface air temperature trends. Geophys Res Lett 34(8), L08703. doi:10.1029/2006g1028502 